\title{
Magnetic Resonance Imaging Appearance of Erythema Nodosum: A Case Report
}

\author{
Ankita Chauhan $^{1^{*}}$, Richard Thomas ${ }^{2}$ \\ 1. University of Tennessee Health Science Center/Le Bonheur Children's Hospital, Memphis, TN, USA \\ 2. Department of Radiology, John R. Oishei Children's Hospital, Buffalo, USA \\ * Correspondence: Ankita Chauhan, MD, Department of Radiodiagnosis, Le Bonheur's Children Hospital, Memphis, \\ Tennessee 38103, USA \\ $(-4$ dranku23@gmail.com)
}

Radiology Case. 2021 Jan; 15(1):21-29 :: $\quad$ DOI: 10.3941/jrcr.v15i1.3919

\begin{abstract}
Erythema nodosum (EN) is the commonest inflammation of the subcutaneous fat tissue (panniculitis). Erythema nodosum (EN) requires an interdisciplinary approach and exclusion of all underlying causes. We present a case of an 18-year-old female with a history of recurrent streptococcal infections over the years, who developed pain and swelling in the left ankle. To evaluate the persistent ankle swelling, the physician ordered a magnetic resonance imaging (MRI) of the left lower extremity. The MRI appearance of EN has not been described in detail in the literature so far.
\end{abstract}

\section{CASE REPORT}

\section{CASE REPORT}

We present a case of an 18-year-old female with a sore throat and swelling in the left ankle. She had a positive history of recurrent streptococcal pharyngitis and tonsillitis annually for eight years. Her exam showed enlarged erythematous tonsils. She had multiple small, palpable, tender nodules on her lower legs. She had a positive rapid streptococcal test. Creactive protein levels were elevated, measuring $20 \mathrm{mg} / \mathrm{L}$ (normal value $<10 \mathrm{mg} / \mathrm{L}$ ). Complete blood count $(\mathrm{CBC})$ and erythrocyte sedimentation rate (ESR) were normal. Antinuclear antibodies (ANA) and autoantibodies were negative. Muscle enzymes were normal. Chest radiograph findings were within normal limits. She was diagnosed with EN and advised to complete a course of oral steroids. There was an excellent response to oral steroids. Symptoms recurred after the steroid course ended, and she developed new skin lesions and ankle swelling. On examination, she had bilateral ankle swelling, more on the left side. Her range of movements
(ROM) was within normal limits, though associated with mild tenderness. The remainder of joints were without warmth, swelling and had a normal range of movements (ROM). Her symptoms persisted for five months. Magnetic resonance imaging (MRI) was ordered to look for a pathology that may explain why the patient had persistent swelling and pain in her ankle or the reason for the exercise-related cramping of her leg muscles. Magnetic resonance imaging (MRI) of the left lower extremity was performed with a 3 Tesla MRI scanner. The following sequences were obtained: T1-weighted, T2weighted, fat-saturated T1-weighted, fat-saturated T2weighted, STIR, T2*, and post-contrast fat-saturated T1weighted. MRI revealed tenosynovitis involving a few tendons and retrocalcaneal bursitis, thereby explaining the reason why our patient was having ankle pain. The osseous signal was normal. There were no findings to suggest synovitis or erosive arthropathy. 
Incidentally, we noticed the MRI appearance of the erythema nodosum lesions on different image sequences. As very limited information is available in the literature regarding imaging characterization of EN lesions, we formulated our case report to describe erythema nodosum appearance in various imaging sequences. MRI demonstrated multiple enhancing ill-defined subcutaneous nodules, most numerous along the lateral aspect of the shin extending down to below the lateral malleolus (Figure 1-7). These nodules were clinically diagnosed as erythema nodosum lesions based on their classic appearance and behavior by the pediatric rheumatology service of our Hospital. EN lesions showed a low-to-intermediate signal on the T1-weighted images (Figure 1). On fat-saturated T1-weighted images, EN lesions were mildly hyperintense, with signal brighter than the muscle signal (Figure 2-3). On T2-weighted images, it showed a heterogeneously hypointense signal, but appeared hyperintense to the muscle/tendon signal (Figure 4). EN showed a hyperintense signal on T2-weighted fat-saturated and STIR images (Figure 5-6). There was no blooming on the $\mathrm{T} 2 *$ sequence to suggest calcification or hemosiderin staining (Figure 7).

To achieve successful control of the EN lesions, our patient underwent tonsillectomy recently. The EN lesions have resolved in our patient, thereby supporting and confirming the clinical diagnosis of Streptococcal infections (tonsillitis) as the reason for our patient's EN lesions.

\section{DISCUSSION}

Inflammation of the subcutaneous fat is called panniculitis, frequently presenting with inflammatory nodules or plaques. Panniculitis has a wide variety of etiological subtypes; it may be due to infection, external insults, malignancy and inflammatory diseases. Erythema nodosum (EN), the most frequent clinical presentation of panniculitis, is a reactive process triggered by a wide variety of stimuli [1].

\section{Etiology \& Demographics:}

While up to $55 \%$ of EN is considered idiopathic [1], the most common causes include infections, drugs, systemic illnesses such as sarcoidosis and inflammatory bowel disease (IBD), pregnancy and malignancy (Table 1). Hypersensitivity reactions to medications such as oral contraceptives, antibiotics (amoxicillin and especially sulfonamides), Proton pump inhibitors, and leukotriene modifiers may cause EN lesions [2].

Erythema nodosum occurs three-to-five times more frequently in women, mostly in the second and fourth decades of life [3]. However, EN in children has a sex ratio of 1:1 [2]. An increased prevalence of EN in the first half of the calendar year is associated with more frequent streptococcal infection at this time of year. The familial tendency to $\mathrm{EN}$ is also related to infectious etiology [4].

\section{Clinical \& Imaging findings:}

EN appears as erythematous, painful rounded lumps, typically $1-6 \mathrm{~cm}$ in diameter. It may involve any joint. However, ankles, knees and wrists are affected most [5]. EN is usually symmetric in presentation, and the lesions develop mostly on the anterior surface of the lower extremities. These lesions do not demonstrate necrosis and resolve spontaneously within 2-8 weeks without leaving scars.

It is important to remember that the diagnostic process in the case of erythema nodosum should be especially careful, because the cause of the skin lesion may be missed. In each case of erythema nodosum, at least radiograph of the chest should be performed, and sometimes even computed tomography is necessary [3].

In our case, $\mathrm{EN}$ was presumed to be the presenting feature of a systemic process. Our patient had no symptoms of Behcet's or inflammatory bowel disease (IBD) and had a normal chest radiograph, lysozyme, and angiotensinconverting enzyme (ACE), which made Sarcoid highly unlikely. Panniculitis can be associated with polyarteritis nodosa (PAN), particularly cutaneous PAN and systemic lupus erythematosus (SLE) and related disorders. The extensive laboratory workup, including ANA, and inflammatory markers were within normal limits. Nothing substantial is available in the literature regarding the imaging features of EN lesions. Through our case, we introduce the MRI appearance of EN in the various MR sequences (Table 2).

\section{Treatment \& Prognosis:}

$\mathrm{EN}$, often, is a sign of a serious but potentially treatable disorder. EN may be the presenting feature of a systemic process, such as Behcet's, sarcoidosis and inflammatory bowel disease (IBD) [6-8]. An interdisciplinary approach to exclude all underlying causes is essential in the management of EN [3].

The most definitive means of alleviating erythema nodosum is to treat the underlying disease process [2]. Discontinuation of the causative medications should be considered once erythema nodosum is diagnosed [2].

In our case, tonsillectomy was performed to control EN episodes successfully.

\section{Differential Diagnosis:}

The differential diagnosis list is broad. The most common differentials include $\alpha 1$-antitrypsin deficiency, cytophagic histiocytic panniculitis (a lymphoma), lupus erythematosus profundus (lupus panniculitis) and nodular fat necrosis. Less common ones are necrobiosis lipoidica, necrobiotic xanthogranuloma, scleroderma, subcutaneous granuloma [2].

\section{Conclusion:}

$\mathrm{EN}$, seen more frequently in younger females, requires an interdisciplinary approach to exclude all underlying causes. Streptococcal infections are the most common cause identified. The diagnosis is usually clinical. The physicians, 
including the radiologists, dermatologists, and rheumatologists, should be aware of how EN lesions look on MRI, to avoid misdiagnosis and cause a delay in the treatment. To the best of our knowledge, the MRI appearance of erythema nodosum on so many different MR sequences in a single patient has not been described in the literature.

\section{TEACHING POINT}

Erythema nodosum (EN) requires an interdisciplinary approach and exclusion of all underlying causes. The information on the imaging appearance of the EN lesions is minimal. The physicians should be aware of how EN lesions look on MRI, to avoid misdiagnosis and cause a delay in the treatment.

\section{REFERENCES}

1. Blake T, Manahan M, Rodins K. Erythema nodosum - a review of an uncommon panniculitis. Dermatol Online J. 2014, 20(4):22376. PMID: 24746312

2. Schwartz RA, Nervi SJ. Erythema nodosum: a sign of systemic disease. Am Fam Physician. 2007, 75:695-700. PMID: 17375516.

3. Chowaniec M, Starba A, Wiland P. Erythema nodosum review of the literature. Reumatologia. 2016, 54:79-82. PMID: 27407284.

4. Requena L, Sánchez YE. Erythema nodosum. Semin Cutan Med Surg. 2007, 26:114-125. PMID: 17544964.

5. Whig J, Mahajan V, Kashyap A, Gupta S. Erythema nodosum: Atypical presentation of common disease. Lung India. 2010, 27:181-182. PMID: 20931044.

6. Topcuoglu OM, Ozcan HN, Akpinar E, Topcuoglu ED, Oguz B, Haliloglu M. Imaging findings of pediatric radiologic emergencies. AJR. 2015, 204:428-439. PMID: 25615767.

7. Chae EJ, Do KH, Seo JB, et al. Radiologic and Clinical Findings of Behçet Disease: Comprehensive Review of Multisystemic Involvement. RadioGraphics. 2008, 28:e31. PMID: 18603663.

8. Avalos-Díaz E, Judith DomínguezCherit J, Herrera-Esparza R. Cutaneous manifestations of spondyloarthritis. Int. J. Clin. Rheumatol. 2012, 7:55-61. URL: https://www.openaccessjournals.com/articles/cutaneousmanifestations-of-spondyloarthritis.pdf 


\section{FIGURES}

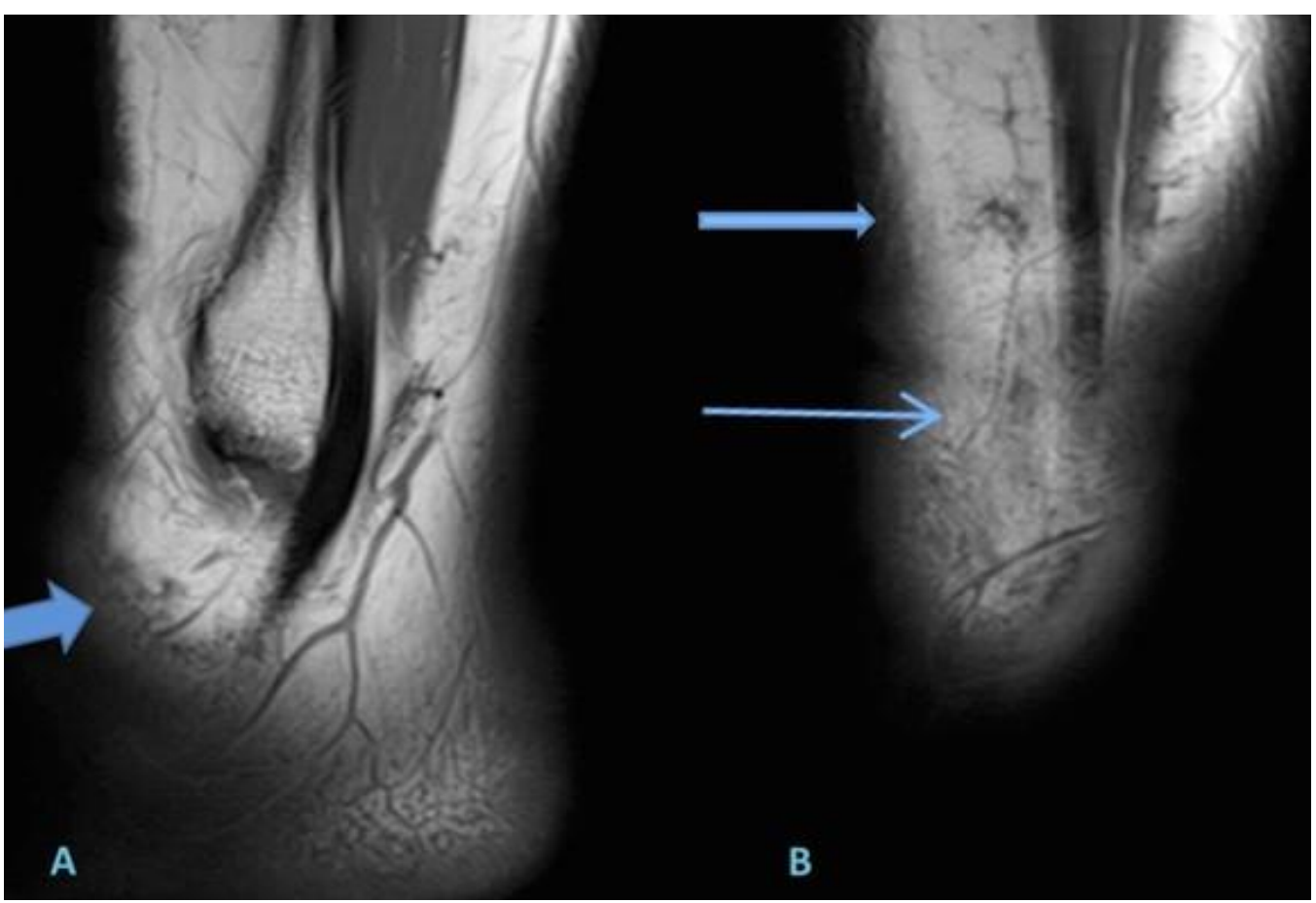

Figure 1: 18-year-old female with Erythema nodosum.

Findings: Sagittal T1-weighted images (A and B) of the left lower leg demonstrate low-to-intermediate signal of the Erythema nodosum lesions (arrows).

Technique: Toshiba 3 Tesla Magnetic Resonance System. Turbo spin-echo T1-weighted sequence (slice thickness 3mm, TR: 493, TE: 10, flip angle: 90).

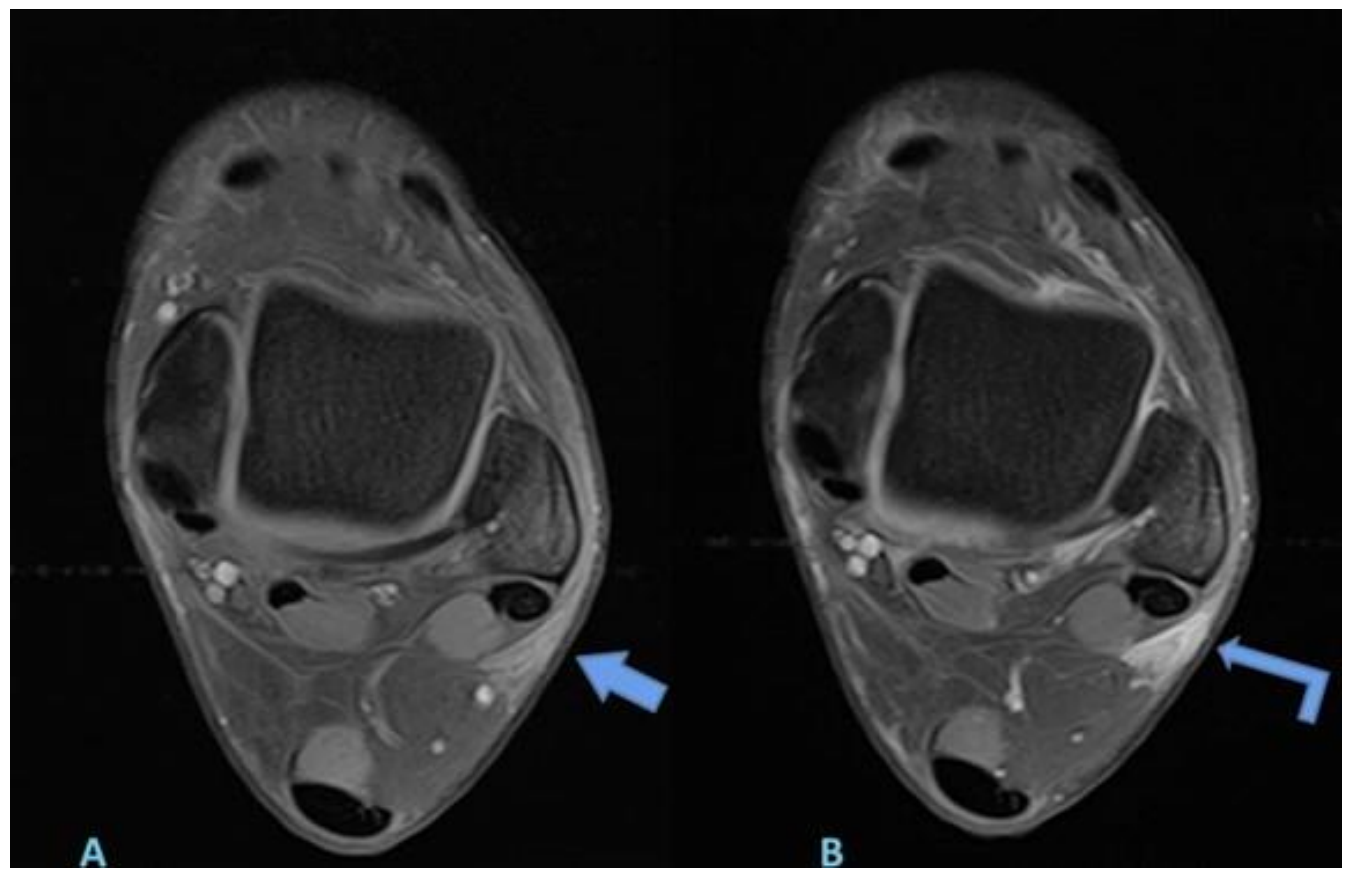

Figure 2: 18-year-old female with Erythema nodosum.

Findings: Axial T1-weighted fat-saturated pre-contrast (A) and post-contrast (B) images of the left lower leg demonstrate subtle hyperintense signal of Erythema nodosum lesions (short arrow in A) showing post-contrast enhancement (long arrow in B).

Technique: Toshiba 3 Tesla Magnetic Resonance System. T1-weighted fat-saturated sequence (slice thickness 3mm, TR: 743, TE: 10, flip angle: 90) before and after administration of $10 \mathrm{~mL}$ Multihance intravenous gadolinium contrast. 


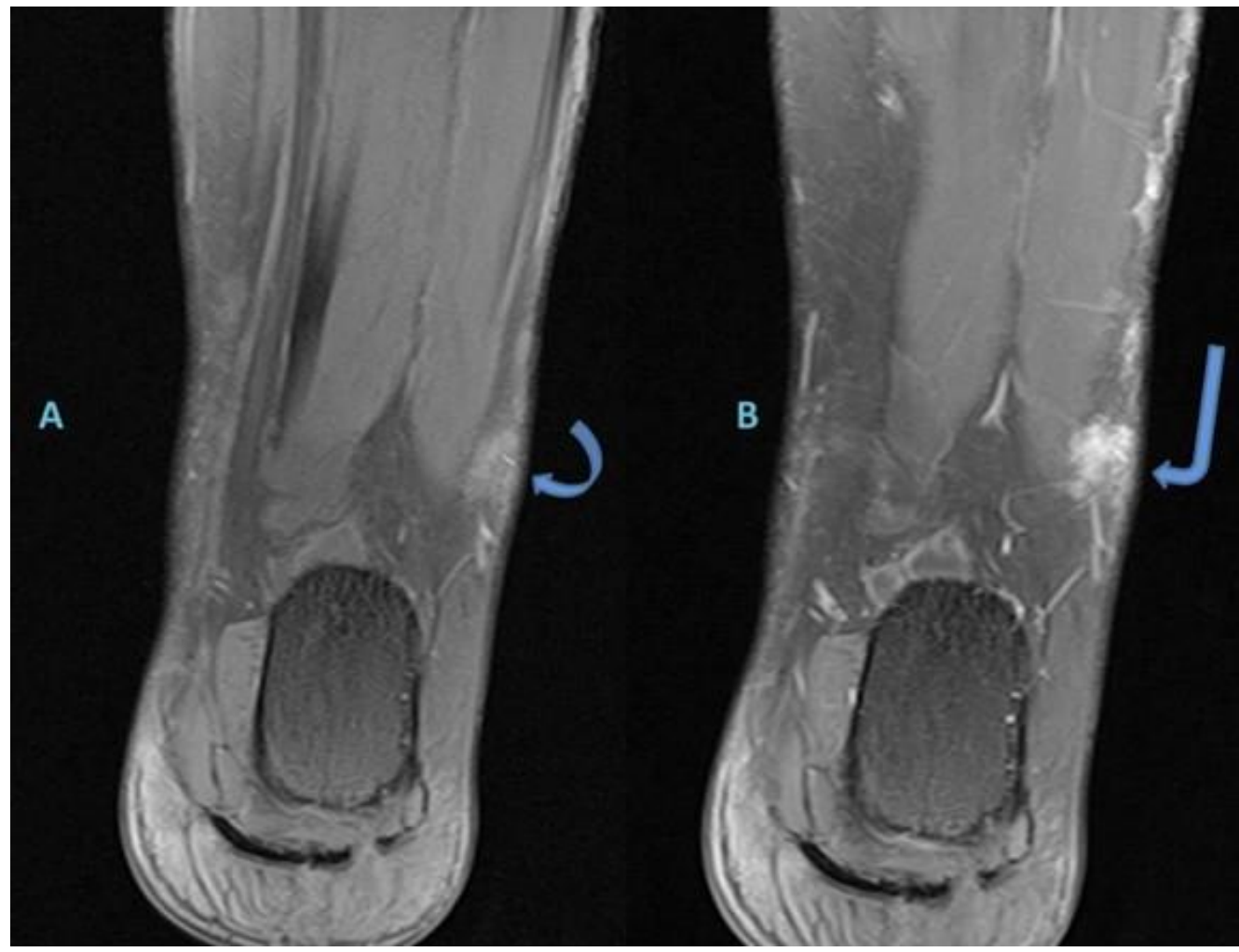

Figure 3: 18-year-old female with Erythema nodosum.

Findings: Coronal T1-weighted fat-saturated pre-contrast (A) and post-contrast (B) images of the left lower leg, demonstrating enhancing ill-defined subcutaneous nodules (arrows).

Technique: Toshiba 3 Tesla Magnetic Resonance System. Coronal T1-weighted fat-saturated sequence (slice thickness 3mm, TR: 612, TE: 10, flip angle: 90) before and after administration of $10 \mathrm{~mL}$ Multihance intravenous gadolinium contrast.

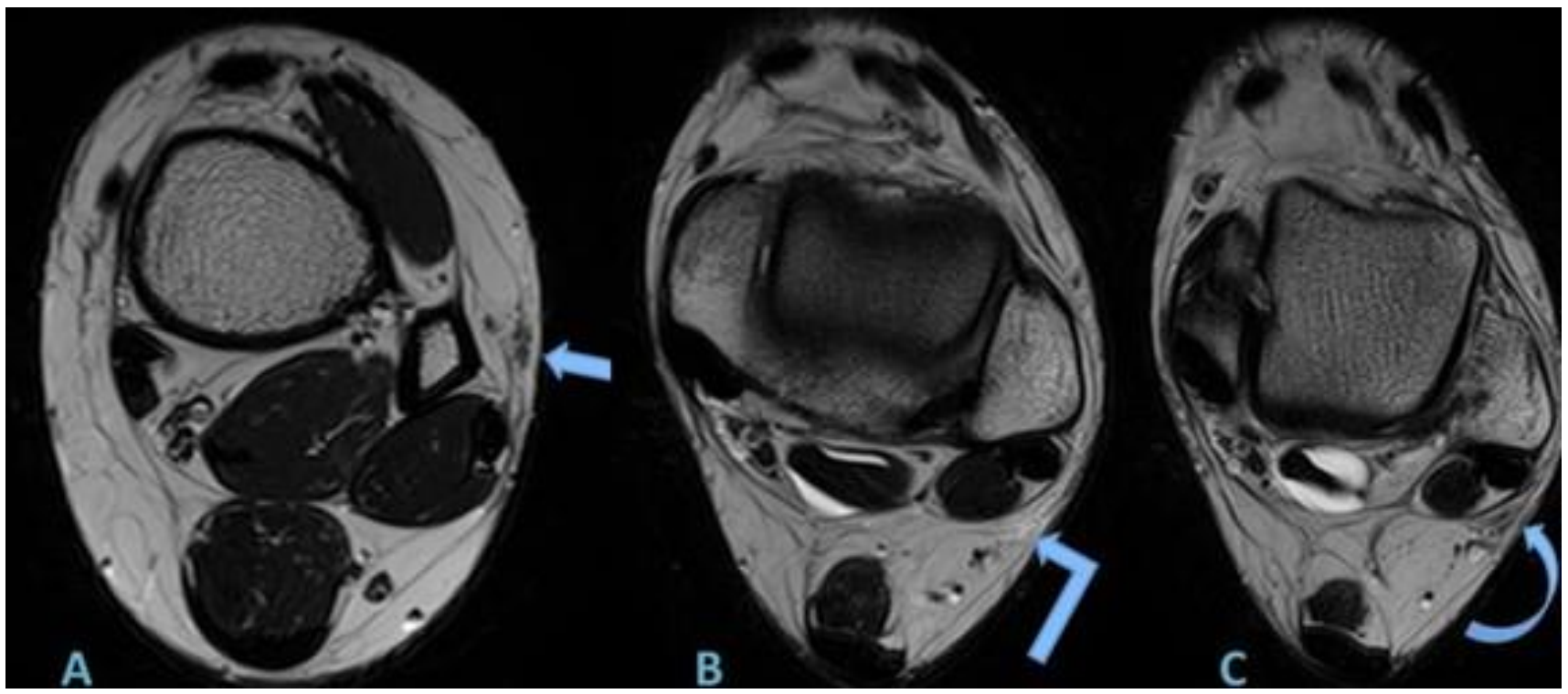

Figure 4: 18-year-old female with Erythema nodosum.

Findings: Axial T2-weighted images (A-C) at the level of distal tibia and fibula showing mixed hypo-to-hyperintense signals of the erythema nodosum lesions (arrows). Erythema nodosum signal is brighter than the muscle.

Technique: Toshiba 3 Tesla Magnetic Resonance System. T2-weighted (slice thickness 3mm, TR: 4490, TE: 100, flip angle: 90). 


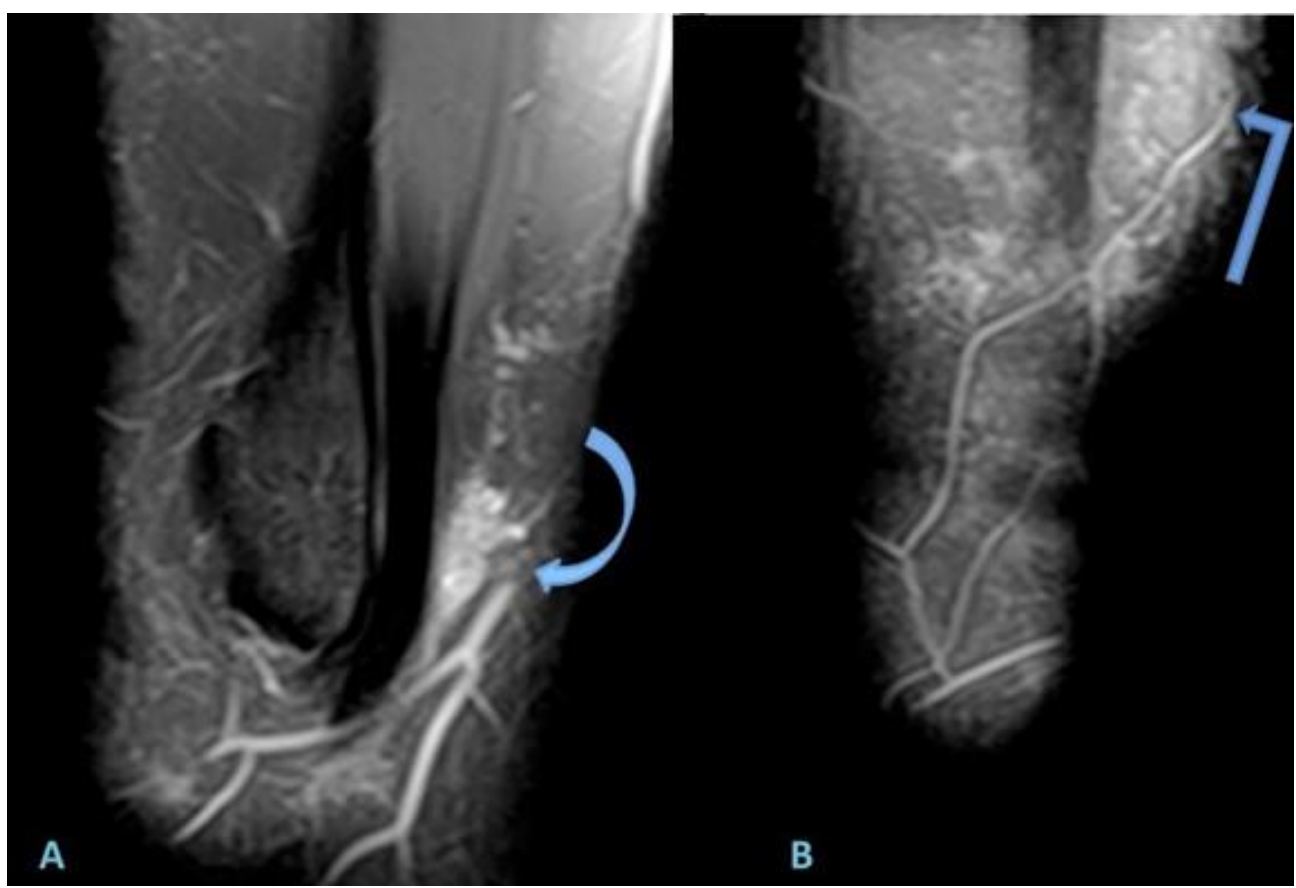

Figure 5: 18-year-old female with Erythema nodosum.

Findings: Sagittal T2-weighted fat-saturated images at the level of the left ankle demonstrating erythema nodosum lesions (arrows) brighter than the muscle.

Technique: Toshiba 3 Tesla Magnetic Resonance System. Sagittal T2-weighted fat-saturated sequence (slice thickness 3mm, TR: 4163, TE: 50, flip angle: 90).

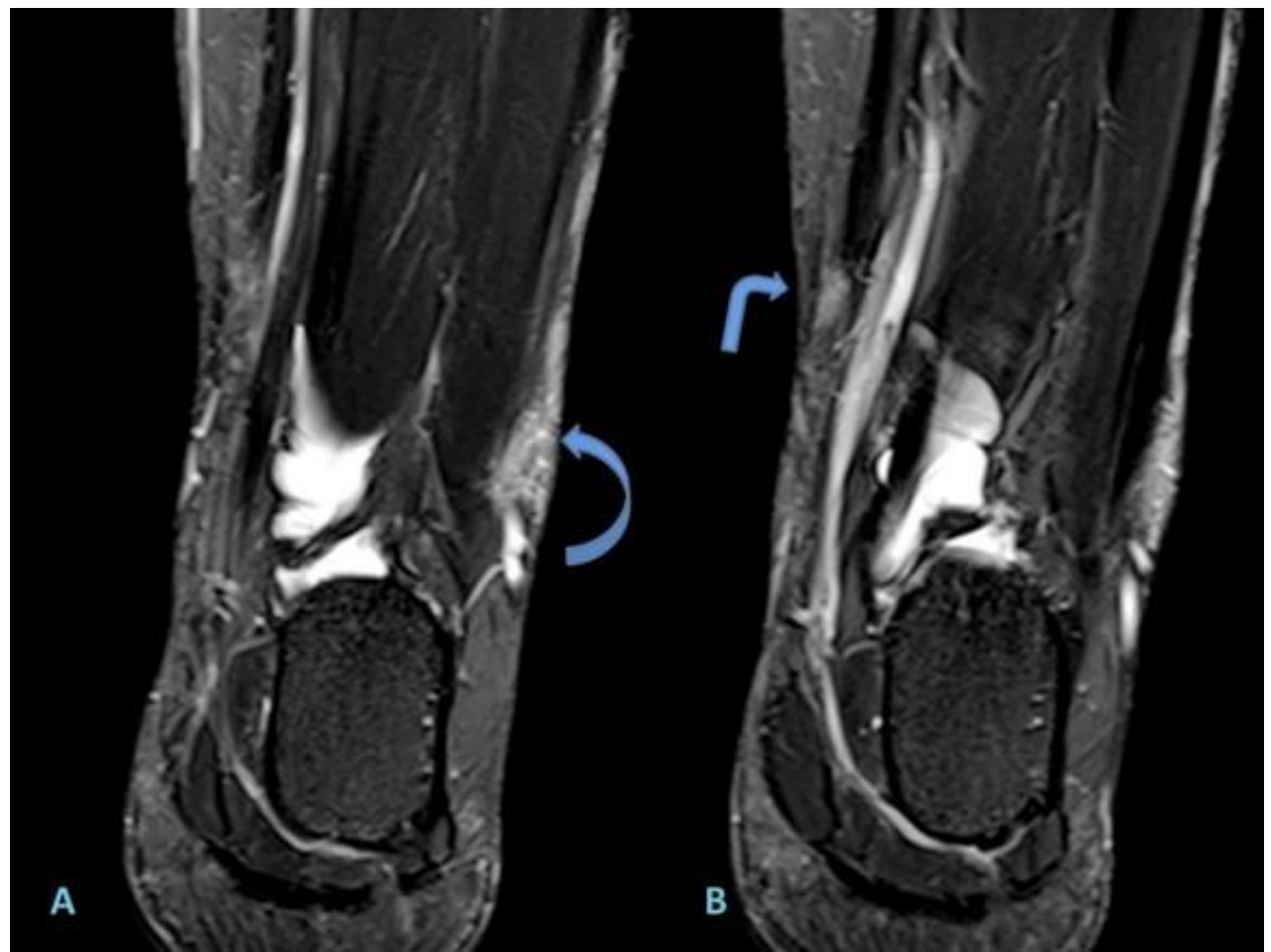

Figure 6: 18-year-old female with Erythema nodosum.

Findings: Coronal STIR images (A, B) of the left lower leg demonstrating hyperintense EN lesions (arrows).

Technique: Toshiba 3 Tesla Magnetic Resonance System. Coronal STIR sequence (slice thickness 3mm, TR: 3800, TE: 56, flip angle: 90). 


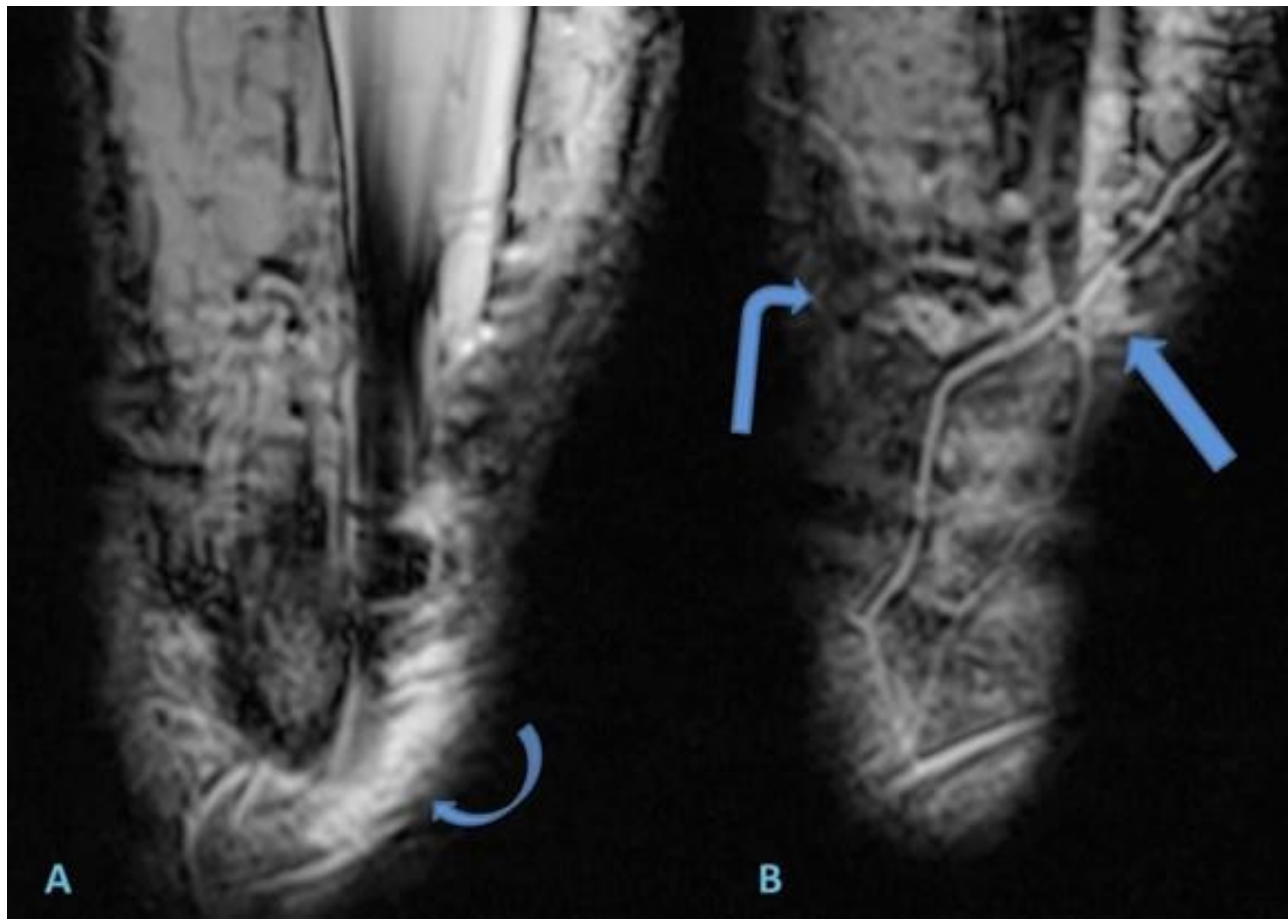

Figure 7: 18-year-old female with Erythema nodosum.

Findings: Sagittal T2-weighted gradient images (A, B) of the left lower leg at the level of EN lesions (arrows) do not demonstrate any blooming.

Technique: Toshiba 3 Tesla Magnetic Resonance System. T2-weighted gradient sequence (slice thickness 3mm, TR: 365.20, TE: 9, flip angle: 15$)$.

\begin{tabular}{|c|c|c|c|}
\hline Etiology & \multicolumn{3}{|c|}{$\begin{array}{l}\text { Idiopathic (Most common) } \\
\text { Infections: Streptococcal pharyngitis (most commonly known cause), tuberculosis } \\
\text { Sarcoidosis } \\
\text { Drugs: sulfonamides, amoxicillin, oral contraceptives } \\
\text { Pregnancy } \\
\text { Enteropathies: regional enteritis, ulcerative colitis }\end{array}$} \\
\hline Incidence & \multicolumn{3}{|c|}{ Increased cases in the first half of the calendar year } \\
\hline Gender ratio & \multicolumn{3}{|c|}{$\begin{array}{l}\text { Adults: Female>Male } \\
\text { Child: No sex predilection }\end{array}$} \\
\hline Age predilection & \multicolumn{3}{|c|}{ Most common in $10-40$ years } \\
\hline Treatment & \multicolumn{3}{|c|}{ To treat the underlying disease process } \\
\hline Prognosis & \multicolumn{3}{|c|}{ Good } \\
\hline $\begin{array}{l}\text { Findings on Magnetic } \\
\text { Resonance Imaging }\end{array}$ & $\begin{array}{l}\text { Sequence } \\
\text { T1W } \\
\text { T1 Fat sat } \\
\text { T2W } \\
\text { T2 Fat sat } \\
\text { STIR } \\
\text { T2* gradient }\end{array}$ & $\begin{array}{l}\text { Signal relative to subcutaneous fat } \\
\text { Hypointense } \\
\text { Hyperintense } \\
\text { Hypo-to-hyperintense } \\
\text { Hyperintense } \\
\text { Hyperintense } \\
\text { Hyperintense, no blooming }\end{array}$ & $\begin{array}{l}\text { Signal relative to muscle } \\
\text { Iso-hypointense } \\
\text { Hyperintense } \\
\text { Hyperintense } \\
\text { Hyperintense } \\
\text { Hyperintense } \\
\text { Hyperintense, no blooming }\end{array}$ \\
\hline
\end{tabular}

Table 1: Summary table for Erythema Nodosum. 


\begin{tabular}{|c|c|c|}
\hline Disease & Clinical features & Diagnostic features \\
\hline Streptococcal pharyngitis & $\begin{array}{l}\text { - Erythema nodosum may appear two to three } \\
\text { weeks after infection }\end{array}$ & $\begin{array}{l}\text { - Throat culture (group A streptococci), } \\
\text { streptococcal antistreptolysin-O (ASO) titers, } \\
\text { polymerase chain reaction (PCR) assays. } \\
\text { - ASO titers: } 2 \text { times - At the time of diagnosis } \\
\text { and repeat titer within four weeks to assess for } \\
\text { streptococcal infection }\end{array}$ \\
\hline $\begin{array}{l}\text { Tuberculosis and atypical } \\
\text { mycobacterium }\end{array}$ & $\begin{array}{l}\text { - Erythema nodosum is commonly associated } \\
\text { with tuberculosis. Tuberculin skin test and } \\
\text { bacille Calmette-Guérin (BCG) vaccination } \\
\text { are associated with EN }\end{array}$ & $\begin{array}{l}\text { - Tuberculin skin test, chest radiography, } \\
\text { sputum culture for acid-fast bacillus. } \\
\text { - In erythema nodosum patients with positive } \\
\text { Mantoux skin test reactions, antitubercular } \\
\text { therapy should be started without a positively } \\
\text { identified focus of infection }\end{array}$ \\
\hline $\begin{array}{l}\text { Systemic lupus } \\
\text { erythematosus }\end{array}$ & $\begin{array}{l}\text { - Fatigue, fever, arthralgia, } \\
\text { - myalgia, arthritis, Malar rash, hypertension, } \\
\text { hematuria, headache and cognitive problems, } \\
\text { dyspnea, cough, chest and abdominal pain, } \\
\text { nausea }\end{array}$ & $\begin{array}{l}\text { - Increased renal parenchymal echogenicity on } \\
\text { ultrasound examination } \\
\text { - Avascular necrosis of the femoral head } \\
\text { - Mesenteric vasculitis, bowel ischemia, ascites, } \\
\text { intestinal pseudoobstruction } \\
\text { - Pleural effusion, ground-glass opacities and } \\
\text { parenchymal nodules, interstitial lung disease }\end{array}$ \\
\hline Behçet's syndrome & $\begin{array}{l}\text { - Oral and genital ulcers, erythema nodosum, } \\
\text { uveitis, blurred vision, eye pain, } \\
\text { photophobia, abdominal pain, diarrhea, } \\
\text { arthralgia, arthritis }\end{array}$ & $\begin{array}{l}\text { - Pulmonary thromboembolism, pulmonary } \\
\text { infarction, parenchymal ground-glass } \\
\text { opacifications } \\
\text { - Thrombosis of visceral arteries and veins } \\
\text { - Focal or multifocal hyperintense lesions on } \\
\text { T2-weighted MRI at brainstem, cerebellum } \\
\text { and cerebral parenchyma, pseudotumor } \\
\text { cerebri, meningoencephalitis, dural sinus } \\
\text { thrombosis, PRES }\end{array}$ \\
\hline Sarcoidosis & $\begin{array}{l}\text { - Erythema nodosum in sarcoidosis patients of } \\
\text { northern European descent has been } \\
\text { regarded as a good prognostic indicator. } \\
\text { Sarcoidosis with hilar adenopathy, } \\
\text { polyarthritis, and erythema nodosum is } \\
\text { called Löfgren's syndrome and has a good } \\
\text { prognosis. Löfgren's syndrome tends to be } \\
\text { acute and self-limited, resolving in six to } \\
\text { eight weeks, whereas sarcoidosis can be } \\
\text { chronic and progressive. }\end{array}$ & $\begin{array}{l}\text { - Chest radiograph (initial investigation) or CT } \\
\text { chest (bilateral hilar lymphadenopathy) } \\
\text { - Serum angiotensin-converting enzyme (ACE) } \\
\text { levels }\end{array}$ \\
\hline $\begin{array}{l}\text { Inflammatory bowel } \\
\text { disease }\end{array}$ & $\begin{array}{l}\text { - Infectious colitis, ulcerative colitis and } \\
\text { Crohn's disease are associated with erythema } \\
\text { nodosum. Abdominal pain and diarrhea with } \\
\text { erythema nodosum in these is reflective of } \\
\text { acute flare-ups. Firm control of colitis } \\
\text { prevents further erythema nodosum. }\end{array}$ & $\begin{array}{l}\text { - CT abdomen: bowel-wall thickening, } \\
\text { mesenteric edema, lymphadenopathy, luminal } \\
\text { narrowing } \\
\text { - MR enterography to assess disease activity } \\
\text { and extent }\end{array}$ \\
\hline Malignancy & $\begin{array}{l}\text { - Mostly- Lymphoma, leukemia } \\
\text { - Rarely - carcinoid, colorectal carcinoma and } \\
\text { pancreatic cancers } \\
\text { - In a patient with a history of Hodgkin's } \\
\text { disease, the development of erythema } \\
\text { nodosum may reflect recurrence. }\end{array}$ & $\begin{array}{l}\text { - An exhaustive workup for malignancy should } \\
\text { be planned if there is a clinical concern for } \\
\text { malignancy (features such as unexplained } \\
\text { weight loss). }\end{array}$ \\
\hline
\end{tabular}

Table 2: Differential diagnosis table for Erythema nodosum $[2,6]$. 


\section{ABBREVIATIONS}

$\mathrm{ACE}=$ Angiotensin-converting enzyme

ANA $=$ Antinuclear antibodies

$\mathrm{CBC}=$ Complete blood count

$\mathrm{EN}=$ Erythema nodosum

$\mathrm{ESR}=$ Erythrocyte sedimentation rate

IBD = Inflammatory bowel disease

MRI = Magnetic resonance imaging

PAN = Polyarteritis nodosa

ROM = Range of movements

SLE $=$ Systemic lupus erythematous

\section{KEYWORDS}

Erythema nodosum; magnetic resonance imaging; sequences; ankle; streptococcal

\section{Online access}

This publication is online available at:

www.radiologycases.com/index.php/radiologycases/article/view/3919

\section{Peer discussion}

Discuss this manuscript in our protected discussion forum at: www.radiolopolis.com/forums/JRCR

\section{Interactivity}

This publication is available as an interactive article with scroll, window/level, magnify and more features.

Available online at www.RadiologyCases.com

\section{Published by EduRad}

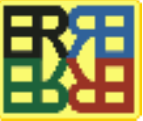

www.EduRad.org 